\title{
Computational Analysis of The Performance of Shaft Furnaces with Partial Replacement of The Burden with Self-Reducing Pellets Containing Biomass
}

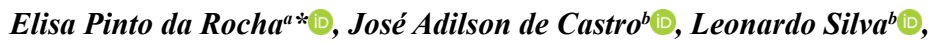 \\ Rayla de Souza Caldas \\ ${ }^{a}$ Universidade Federal do Rio de Janeiro, Av. Aluizio da Silva Gomes, 50, CEP 27930-560, Novo \\ Cavaleiros, Macaé, Rio de Janeiro, RJ, Brasil \\ ${ }^{b}$ Universidade Federal Fluminense, Av. dos Trabalhadores 420, CEP 27255-125, Vila Sta. Cecília, \\ Volta Redonda, RJ, Brasil
}

Received: September 21, 2019; Revised: November 26, 2019; Accepted: December 19, 2019

The shaft furnace knowed Midrex ${ }^{\mathrm{TM}}$ is used for the production of direct reduced iron with the use of reformed gas. Another process based on shaft reactors is the Tecnored process, which exhibits the great advantage of using self-reducing agglomerates. Therefore, it was proposed a combination of the shaft furnace for direct reduction with self-reducing pellet burden. In addition, with the aim of improving the furnace efficiency and reducing the need for reformed gas, the injection of natural gas and oxygen into the bustle region is proposed. Thus, it is possible exploit the advantages of direct reduction involving high amounts of hydrogen and faster reactions of the self-reducing process to decrease the $\mathrm{CO}_{2}$ emission, compared to that of blast furnace. The energy profile, productivity, and carbon emission of the traditional shaft furnace were compared with the simulated results after partial replacement of the burden with self-reducing pellets containing fines of elephant grass charcoal. The simulation results for a combination of $15 \%$ of self-reducing pellets in the burden with $2.5 \%$ oxygen and natural gas injection were the best among the scenarios simulated, with the productivity being $2.7 \mathrm{ton} / \mathrm{m}^{3}$ day and the decrease in the amount of reformed gas being $10 \%$.

Keywords: numerical simulation, shaft furnace, self-reducing pellets, biomass.

\section{Introduction}

The shaft furnace used in direct reduction processes has some advantages, such as lower energy demand due the absence of metal melting, the use of different sources of reducing agents, the use of reformed gas as a reducing agent in the fuel option, and the produced sponge iron exhibiting a lower carbon concentration when compared with that of pig iron, which can demand less refining operations. These technologies are especially attractive on a particular economic and market situation where the demand for steel can be attended by compact reactors providing high energy efficiency.

The shaft furnace is a continuous flow reactor that is charged with iron ore pellets and lump iron ores that descend by gravity while they are reduced to iron by the reducing gas in counter-current flow. The phenomena that take place within the reactor are complex and involve multiple phases and chemical species. In order to understand the inner phenomena, it is convenient to distinguish four different zones in the furnace: heating, reducing, transition, and cooling zones. In the reduction zone, the transformation of the iron oxides to iron occurs at temperatures above $900^{\circ} \mathrm{C}$, concluding in the cooling zone, where the product is cooled and carburized.

A large number of mathematical models have been proposed to predict the direct reduction occurring in the shaft furnace by using transport phenomenom ${ }^{1-11}$. The models have been successfully used to forecast the energy balance, productivity, and overall mass balance of the furnace. These models have been useful in analyzing new operating conditions and proposals for new developments ${ }^{5-9}$.

However, owing to the difficulty in describing the complex phenomena, the computational models proposed in the literature have been simplified ${ }^{5-9}$. The assumptions for the transport equations concerning spatial analysis, which can be one-dimensional ${ }^{1,2}$ or two-dimensional, are commonly applied ${ }^{3-5}$; yet, the analysis is carried out in the steady state regime ${ }^{6,7}$.

A combination of the shaft furnace for the production of DRI (direct reduced iron) with partial replacement of the burden with self-reducing pellets has not yet been investigated, but, there are proposals of the variations in the burden of the shaft furnaces investigated by means of computational resources, however, those proposals are in terms of changing of the burden distribution ${ }^{12,13}$. Zhou et al, have proposed that the burden of the blast furnace was charged alternating coke and ore layers of different permeability. It was observed the energy profile of the blast furnace and, when the burden is mixed, the gas and burden along the radial direction are of the same temperature, and the gas temperature and pressure at the furnace wall are in good agreement with the measured data in the operating blast furnace. This also may be noted in Austin et al. ${ }^{14,15}$ and Castro et al.'s research ${ }^{16}$. 
Previous investigations of the behavior of the shaft furnace charged with pellets and using reformed reducing gas were performed by using computational simulations, and the results suggested the possibility of reaching around $93 \%$ of the metallization degree ${ }^{8-10}$. However, a large amount of reducing gas is required, and hydrogen reduction is efficient only at high temperatures. Matos et al. ${ }^{17}$ investigated the use of self-reducing briquettes in a mini blast furnace and concluded that both the thermal reserve zone and the fuel rate decreased. A combination of these techniques was proposed by Castro et al. ${ }^{11}$ and the results showed promising features. However, further investigations are required to confirm and suggest a better combination of the operational parameters.

This study has important advantages with regard to the inner phenomena, in that it is expected to improve the efficiency of the process owing to the high reactivity resulting from the bigger contact area among the reactants and the presence of a larger inner porous area, compared to that of DRI pellets. Furthermore, the shaft furnace reactor can be made more compact (shorter), and some studies have suggested that the specific $\mathrm{CO}_{2}$ emissions could be decreased ${ }^{10,11}$. However, a balance of the inner porosity with a suitable mechanical resistance is required. Therefore, to investigate the feasibility of these concepts, it was developed a multiphase and multicomponent mathematical model based on mass, momentum, and energy conservation equations for predicting the inner temperature distribution of a shaft furnace on an industrial scale. It was proposed rate equations that represent the new raw material used in the model, based on previous experimental studies ${ }^{18}$ and for DRI pellets with composition considered in previous works ${ }^{10,11,19}$. It was developed simulation scenarios based on a reference case involving actual operation and those based on partial substitution of the charge with SRP (self reduced pellet).

\section{Materials and Methods}

The methodological approach considered in this study comprised formulation of a detailed model based on multiphase and multicomponent phenomenom and the complementary rate equations determined experimentally to account for the overall rate of the new self-reducing raw material using CEG (charcoal from elephant grass). In this model, the shaft furnace is described as a multicomponent multiphase reactor, where the pellets are treated as phases of different sizes and compositions; these phases interact among themselves as lumps and gaseous phases to exchange energy, mass, and momentum. The energy, mass, and momentum interactions among the granular particles were computed by considering the characteristics of the granular material.

The kinetic rate equations for the SRP and the composition parameters for the implementation of the model were obtained experimentally by the slow sample heating (heat rate of $5^{\circ} \mathrm{C} / \mathrm{min}$ ) until to reach three different temperatures and so, each temperature was maintained in isothermal runs until the chemical transformations are completed, totally. The experiments were performed in a TGA/DSC Q600 furnace using inert atmosphere. The kinetic parameters used in this study were previously published by the authors ${ }^{18}$.

The shaft furnace burden in the model of this paper was composed by iron ore, SRP and DRI pellets, coke and others. So, in the Table 1 the final compositions of the SRP, DRI pellets, CEG, and materials for producing the SRP with biomass, are listed. For mixture of SRP, $20 \%$ of its composition is CEG.

An example of the reaction rates measured in this study is shown in Figure 1. The time evolution of the mass conversion fraction exhibited the typical behavior for isothermal conditions, which were used to determine the kinetic rate constant based on Arrhenius plot ${ }^{18}$. A low heating rate was used until the temperatures $900{ }^{\circ} \mathrm{C}, 1000{ }^{\circ} \mathrm{C}$, and $1100{ }^{\circ} \mathrm{C}$ were reached, therefore, the samples were kept in a constant temperature range for one hour. Details of the experimental runs and rate formulations can be found elsewhere ${ }^{18}$.

The time evolution of the converted samples can be characterized as follows. Above $300^{\circ} \mathrm{C}$, the change in mass is explained by the release of combined associated water molecules through vaporization, since $\mathrm{H}_{2} \mathrm{O}$ molecules can be associated to molecules of iron oxides, like $\mathrm{FeO}(\mathrm{OH})$ and $\mathrm{Fe}^{+3} \mathrm{O}(\mathrm{OH})$, and calcium oxide $\left(\mathrm{Ca}(\mathrm{OH})_{2}\right)$, apart from being present in the hydrocarbons that compose the carbon source used ${ }^{20-23}$. With continuous heating up to $600{ }^{\circ} \mathrm{C}$ for around $120 \mathrm{~min}$, a chemical transformation occurs due to the breaking of the molecules of the volatile materials, followed by $\mathrm{CaCO}_{3}$ decomposition and the solution loss reaction; this is because this type of carbon source is more reactive than coke owing to its porosity and activation energy ${ }^{23}$.

From this moment onwards, the change in mass is abrupt, because, as the appropriate temperature is reached, it favors the indirect reduction of the oxides by the gaseous product $\mathrm{CO}$ : $\mathrm{Fe}_{3} \mathrm{O}_{4} \rightarrow \mathrm{FeO}$ and $\mathrm{FeO} \rightarrow \mathrm{Fe}$, which is represented by the two high peaks observed beyond $180 \mathrm{~min}$ at $1100{ }^{\circ} \mathrm{C}$ (Figure 1 ).

Table 1. Chemical compositions of the feed charge of the shaft furnace simulation.

\begin{tabular}{|c|c|c|c|c|c|c|c|c|c|c|c|c|c|c|}
\hline \% Compounds & $\mathrm{Fe}_{2} \mathrm{O}_{3}$ & $\mathrm{FeO}$ & $\mathrm{SiO}_{2}$ & $\mathrm{Al}_{2} \mathrm{O}_{3}$ & $\mathrm{CaO}$ & MgO & $\mathrm{ZnO}$ & $\mathbf{P}$ & $\mathbf{S}$ & MnO & PbO & $\mathrm{C}_{\text {fix }}$ & Vol. & Ash. \\
\hline SRP & 53.5 & 0.41 & 1.12 & 0.29 & 8.07 & 1.32 & 3.43 & 0.02 & 0.32 & 0.71 & 0.05 & 11.24 & 6.52 & 2.2 \\
\hline DRI* & 96.71 & 0.39 & 1.5 & 0.42 & 0.84 & 0.11 & 0 & 0 & 0 & 0 & 0 & 0 & 0 & 0 \\
\hline Charcoal & 0 & 0 & 0 & 0 & 0 & 0 & 0 & 0 & 0.2 & 0 & 0 & 56.2 & 32.6 & 11 \\
\hline Ashes & 0.24 & 0 & 9.21 & 0.51 & 0.47 & 0.47 & 0 & 0.19 & 0 & 0 & 0 & 0 & 0 & 0 \\
\hline
\end{tabular}

* Composition of DRI was obtained from author ${ }^{10,11,19}$. 


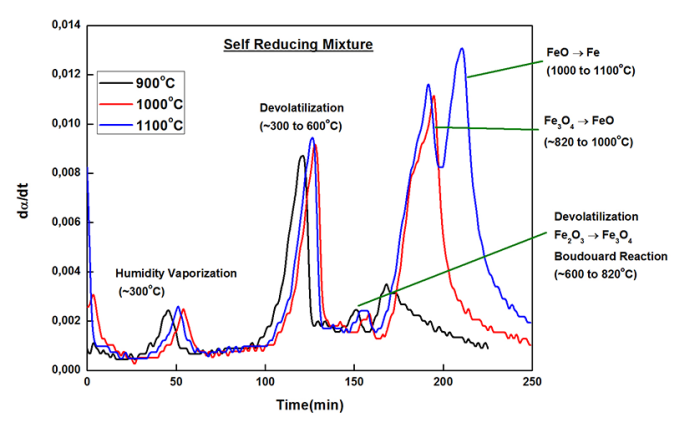

Figure 1. Result of thermogravimetric analysis of the self-reducing mixture in inert atmosphere.

\subsection{Calculation}

The computational model was implemented with the reaction kinetic constants obtained experimentally. The system of differential equations was solved through the finite volume technique by using suitable initial and boundary conditions. The solid burden inlet was interactively adjusted until the final metallization reached $95 \%$ in order to compare the calculations on the same basis. The main output parameters were obtained, namely, the productivity, bustle gas pressure, and residence time of the charge in the furnace, as schematically shown in Figure 2.

The governing equations were solved through the finite volume technique that was applied to a non-orthogonal mesh by using Fortran software ${ }^{9-11,16}$. Equation 1 is the governing equation that describes the phenomena of mass, momentum, and energy transfers for each species $i$ in phase $\mathrm{k}$, where the sources terms $\left(\mathrm{S}_{\varphi \mathrm{k}}\right)$ represent the interactions among other phases in terms of the momentum, energy, and mass transfers involved in the chemical reactions. The transfer coefficient $\left(\Gamma_{\varphi \mathrm{k}}\right)$ assumes different meanings depending on the equation solved. The details pertaining to these model principles have been previously published by Castro et al. ${ }^{8-11,16}$.

$$
\underbrace{\frac{\partial\left(p_{i} \varepsilon_{i} \phi_{k}\right)}{\partial t}}_{\text {Transient Term }}+\underbrace{\operatorname{div}\left(p_{i} \varepsilon_{i} \vec{U}_{i} \phi_{k}\right)}_{\text {Convective Term }}=\underbrace{\operatorname{div}\left(\Gamma_{\phi k} \operatorname{grand}\left(\phi_{k}\right)\right)}_{\text {Difusive Term }}+\underbrace{S_{\phi k}}_{\text {Source Term }}
$$

The subscripts $i, j$, and $k$ represent the classes of pellets considered in the feed charge and the components of the directions of the coordinates, respectively. The subscripts $\mathrm{g}$ and s represent gaseous and solid species, respectively, $\mathrm{n}$ represents a chemical species, and $\mathrm{m}$ is the number of reactions. The parameters that appear in the set of equations listed above are defined in the nomenclature list below.

These equations are coupled with the chemical reaction rates of the self-reformation and self-reduction of $\mathrm{CO}$ and $\mathrm{H}_{2}$ and solved simultaneously.

The governing equations are described for the solid and gaseous phases of each phenomenon, as presented in Table 2 .

The chemical species considered in this model are summarized in Table 3.

The rates of the reactions occurring among the chemical species directly affect the governing equations and can be found in the literature ${ }^{8-11,16}$.

According to the assumptions mentioned, seven operating cases of the furnace were proposed: the first case is the reference for the other cases, and, for the other six cases, new operational conditions are proposed for analyzing the partial substitution of the charge with SRP.

The base case furnace was simulated by using $100 \%$ of DRI pellets, and the atmosphere displayed the characteristic composition of Midrex furnaces $\left(55.2 \% \mathrm{H}_{2}, 30 \% \mathrm{CO}, 10 \%\right.$ $\mathrm{CO}_{2}$, and $4.8 \% \mathrm{CH}_{4}$ ).

Table 4 shows the cases defined and the operating parameters modified, where the self-reducing charge was

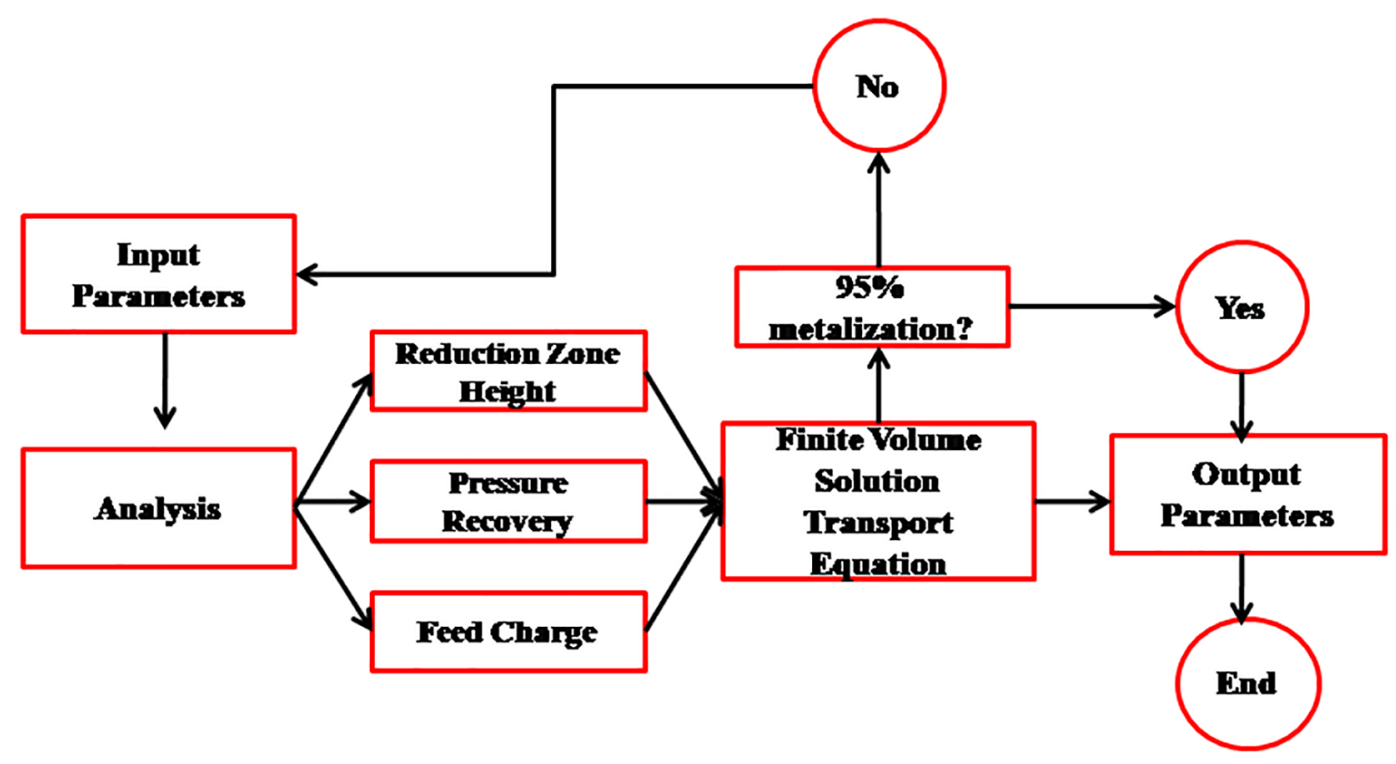

Figure 2. Proposed computational model process flow. 
Table 2. Governing equations for all the species considered in this work.

Granular classes; momentum conservation

$\frac{\partial\left(\rho_{i} \varepsilon_{i} u_{i, k} u_{i, j}\right)}{\partial x_{k}}=\frac{\partial}{\partial x_{k}}\left(\mu_{s} \frac{\partial u_{i, j}}{\partial x_{k}}\right)+F_{j}^{i-l}+F_{i}^{l}$

Mass conservation of solid fractions

$$
\frac{\partial\left(\rho_{i} \varepsilon_{i} u_{i, k}\right)}{\partial x_{k}}=\sum_{m=1}^{\text {Nreacts }} M_{n} r_{m}
$$

Enthalpy balance of solid fractions

$$
\frac{\partial\left(\rho_{i} \varepsilon_{i} u_{i, k} H_{i}\right)}{\partial x_{k}}=\frac{\partial}{\partial x_{k}}\left(\frac{k_{i}}{C_{p, i}} \frac{\partial H_{i}}{\partial x_{k}}\right)+E^{i-l}+\sum_{m=1}^{\text {Nreacts }} \Delta H_{m} r_{m}
$$

Chemical species of solid phases

$\frac{\partial\left(\rho_{i} \varepsilon_{i} u_{i, k} \varnothing_{i}\right)}{\partial x_{k}}=\frac{\partial}{\partial x_{k}}\left(D_{n}^{\text {eff }} \frac{\partial \varnothing_{n}}{\partial x_{k}}\right)-\sum_{m=1}^{\text {Nreacts }} M_{n} r_{m}$

Gas momentum transfer

$\frac{\partial\left(\rho_{g} \varepsilon g u_{g, k} u_{g, j}\right)}{\partial x_{k}}=\frac{\partial}{\partial x_{k}}\left(\mu_{s} \frac{\partial u_{g, j}}{\partial x_{k}}\right)-\frac{\partial P}{\partial x_{j}} F_{j}^{i-j}$

Mass conservation of the gas phase

$\frac{\partial\left(\rho_{g} \varepsilon_{g} u_{g, k}\right)}{\partial x_{k}}=\sum_{m=1}^{\text {Nreacts }} M_{n} r_{m}$

Enthalpy conservation in the gas phase

$\frac{\partial\left(\rho_{g} \varepsilon_{g} u_{g, k} H_{g}\right)}{\partial x_{k}}=\frac{\partial}{\partial x_{k}}\left(\frac{k_{g}}{C_{p g}} \frac{\partial H_{g}}{\partial x_{k}}\right)-E^{g-p}-\sum_{m=1}^{N_{\text {reacts }}} \Delta H_{m} r_{m}$

Chemical species

$\frac{\partial\left(\rho_{g} \varepsilon_{g} u_{g, k} \varnothing_{n}\right)}{\partial x_{k}}=\frac{\partial}{\partial x_{k}}\left(D_{n}^{e f f} \frac{\partial \varnothing_{n}}{\partial x_{k}}\right)-\sum_{m=1}^{\text {Nreacts }} M_{n} r_{m}$

Semi empirical relations for the gas-solid momentum transfer

$\frac{\partial\left(\rho_{g} \varepsilon_{g} u_{g, k} \varnothing_{n}\right)}{\partial x_{k}}=\frac{\partial}{\partial x_{k}}\left(D_{n}^{\text {eff }} \frac{\partial \varnothing_{n}}{\partial x_{k}}\right)-\sum_{m=1}^{\text {Nreacts }} M_{n} r_{m}$

Effective energy transferred between the solid and gaseous phases

$$
\begin{gathered}
F_{j}^{g-i}=\left[1.75 \rho_{g}+\frac{150 \mu_{g}}{\left|\vec{U}_{g}-\vec{U}_{i}\right|}\left(\frac{\varepsilon_{i}}{d_{i} \varphi_{i}}\right)\right] \\
\left(\frac{\varepsilon_{i}}{\left(1-\varepsilon_{i}\right)^{3} d_{i} \varphi_{i}}\right)\left|\vec{U}_{g}-\vec{U}_{i}\right|\left(u_{g, j}-u_{i, j}\right)
\end{gathered}
$$

composed of self-reducing pellets containing charcoal of elephant grass.

The ranges of the operating parameters considered in this model that were altered can be found in Table 5 .

\section{Results and Discussion}

The model developed was implemented to simulate the energy behavior of the shaft furnace according to the scheme presented in Table 4, therefore, the productivity and efficiency of the shaft furnace fed with synthetic gas were provided. The kinetic parameters obtained experimentally, such as the kinetic rate constants, were used in the model ${ }^{18}$.

An initial analysis of the gas flow and temperature distribution in the furnace was performed by considering $100 \%$ of the burden with DRI pellets, as can be seen in Figure 3. The temperature profile suggests typical direct reduction furnace behavior, revealing higher temperatures in the reduction zone and lower temperatures in the cooling zone.

First, the energy profile of the furnace was analyzed when $5 \%$ of the feed load was substituted with SRP. Subsequently, the temperature profile of the furnace was investigated when the proposed changes in the height of the reduction zone and self-reducing charge concentration were effected.

When the base case is compared with Figure 4, which represents the energy profile when $5 \%$ of the load is replaced with self-reducing pellets, it is possible to note that the temperature distribution presents a considerable variation, mainly in the central region of the reduction zone and bustle gas, since the reactions with endothermic character are predominant leading to the reaction and the temperature to stabilize faster, increasing the energy usage in the reduction zone. The self-reducing reaction used the thermal energy of the gas and solid phase while the direct reduction using hydrogen, also endothermic, is slower than the self-reducing process. Figure 4 and 5 reflect these features and larger yellow region is observed in Figure 5.

When $15 \%$ of the feed charge is replaced with SRP, it is possible to take advantage of the high reactivity of the selfreducing agglomerates, as shown in Figure 5 and 6 . However, it is expected that the temperature decreases throughout

\begin{tabular}{|c|c|c|}
\hline Phase & & Chemical Species \\
\hline Gas & & $\mathrm{CO}, \mathrm{CO}_{2}, \mathrm{O}_{2}, \mathrm{H}_{2}, \mathrm{H}_{2} \mathrm{O}, \mathrm{N}_{2}$ \\
\hline \multirow[t]{5}{*}{ Solid } & Iron Ore & $\mathrm{Fe}_{2} \mathrm{O}_{3}, \mathrm{Fe}_{3} \mathrm{O}_{4}, \mathrm{FeO}, \mathrm{Fe}, \mathrm{CaO}, \mathrm{Al}_{2} \mathrm{O}_{3}, \mathrm{MgO}, \mathrm{SiO}_{2}, \mathrm{H}_{2} \mathrm{O}$, gang \\
\hline & DRI Pellet & $\mathrm{Fe}_{2} \mathrm{O}_{3}, \mathrm{Fe}_{3} \mathrm{O}_{4}, \mathrm{FeO}, \mathrm{Fe}, \mathrm{CaO}, \mathrm{Al}_{2} \mathrm{O}_{3}, \mathrm{MgO}, \mathrm{SiO}_{2}, \mathrm{H}_{2} \mathrm{O}$, gang \\
\hline & SRP & $\mathrm{C}$, Volatiles, $\mathrm{Fe}_{2} \mathrm{O}_{3}, \mathrm{Fe}_{3} \mathrm{O}_{4}, \mathrm{FeO}, \mathrm{Fe}, \mathrm{CaO}, \mathrm{Al}_{2} \mathrm{O}_{3}, \mathrm{MgO}, \mathrm{SiO}_{2}, \mathrm{H}_{2} \mathrm{O}$, gang \\
\hline & Coke & $\mathrm{C}$, Volatiles, $\mathrm{SiC}, \mathrm{SiO}_{2}, \mathrm{Al}_{2} \mathrm{O}_{3}, \mathrm{CaO}, \mathrm{MgO}, \mathrm{H}_{2} \mathrm{O}$, gang \\
\hline & CEG & $\mathrm{C}$, Volatiles, $\mathrm{SiC}, \mathrm{SiO}_{2}, \mathrm{Al}_{2} \mathrm{O}_{3}, \mathrm{CaO}, \mathrm{MgO}, \mathrm{H}_{2} \mathrm{O}$, ganga \\
\hline Slag & & $\mathrm{FeO}, \mathrm{SiO}_{2}, \mathrm{Al}_{2} \mathrm{O}_{3}, \mathrm{CaO}, \mathrm{MgO}$, gang \\
\hline
\end{tabular}
the reactor due to the endothermic reactions, therefore, an adjustment was proposed in the feed gas to promote the

Table 3. The chemical species considered in this model. 
Table 4. Cases examined according to the operating parameters modified.

\begin{tabular}{|c|c|c|c|c|c|c|c|}
\hline & & & & Cases & & & \\
\hline Parameters & Base & Case A & Case B & Case C & Case D & Case E & Case F \\
\hline Self-reducing charge & $100 \%$ DRI & $5 \%$ & $15 \%$ & $20 \%$ & & & \\
\hline $\begin{array}{l}\text { Decrease in height in the } \\
\text { reduction zone }\end{array}$ & $\mathrm{x}$ & $\mathrm{x}$ & $\mathrm{x}$ & $15 \%$ & $30 \%$ & $40 \%$ & $40 \%$ \\
\hline $\begin{array}{l}\text { Composition in the cooled } \\
\text { zone }\end{array}$ & $\mathrm{x}$ & $\mathrm{x}$ & $\begin{array}{l}50 \% \mathrm{CH}_{4} \\
\text { reduction }\end{array}$ & $\begin{array}{l}50 \% \mathrm{CH}_{4} \\
\text { reduction }\end{array}$ & $\mathrm{x}$ & $\mathrm{x}$ & $\mathrm{x}$ \\
\hline Composition of bustle gas & $\mathrm{x}$ & $\mathrm{x}$ & $\begin{array}{l}2.5 \% \mathrm{O}_{2} \\
\text { addition }\end{array}$ & $\begin{array}{l}2.5 \% \mathrm{O}_{2} \\
\text { addition }\end{array}$ & $\begin{array}{c}\Delta \mathrm{P} \\
\text { recuperation }\end{array}$ & $\begin{array}{c}\Delta \mathrm{P} \\
\text { recuperation }\end{array}$ & $\begin{array}{c}\text { No } \\
\text { recuperation } \\
\text { of } \Delta \mathrm{P}\end{array}$ \\
\hline
\end{tabular}

Table 5. Parameters modified for the computational simulation.

\begin{tabular}{lc}
\hline Parameters & Operational range \\
\hline Height and volume of the reduction zone & $5.0-7.5 \mathrm{~m}$ and $100-140 \mathrm{~m}^{3}$ \\
Flow rate of the reducing gas & $40-60 \mathrm{NL} / \mathrm{min}$ \\
Fraction of self-reducing charge & $0-20 \%$ \\
Size of the pellets & $4-18 \mathrm{~mm}$ \\
\hline
\end{tabular}

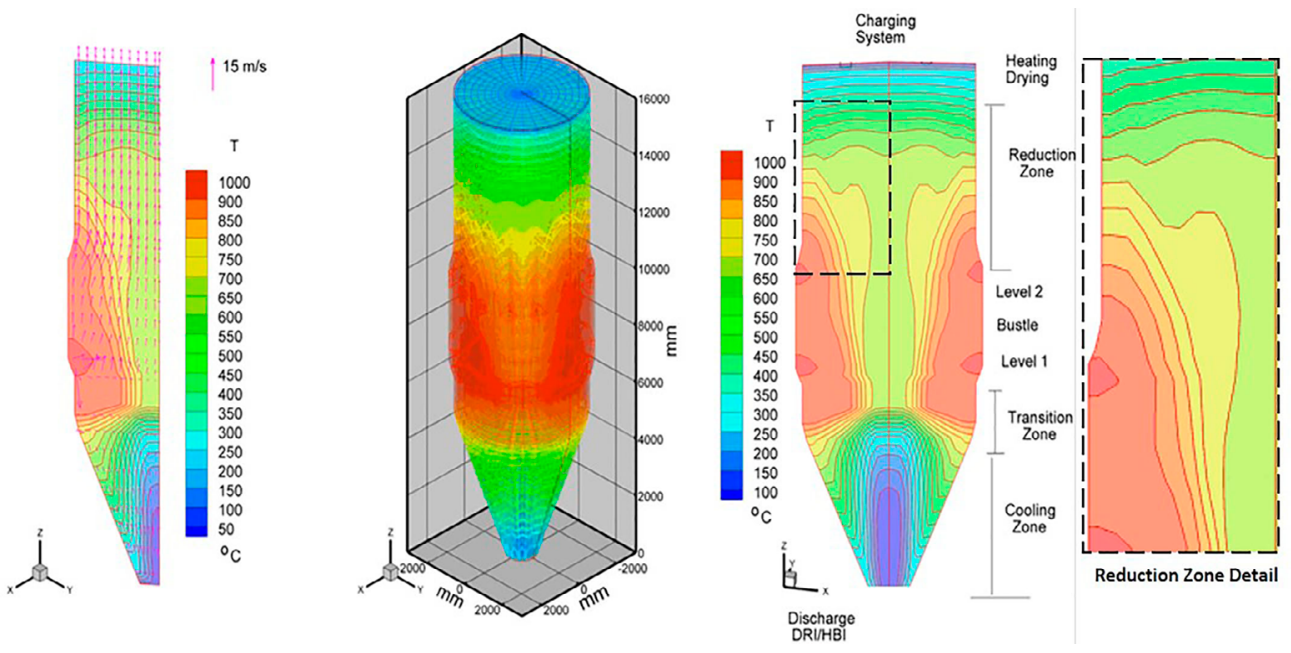

Figure 3. Temperature distributions for the base case of the shaft furnace operation.
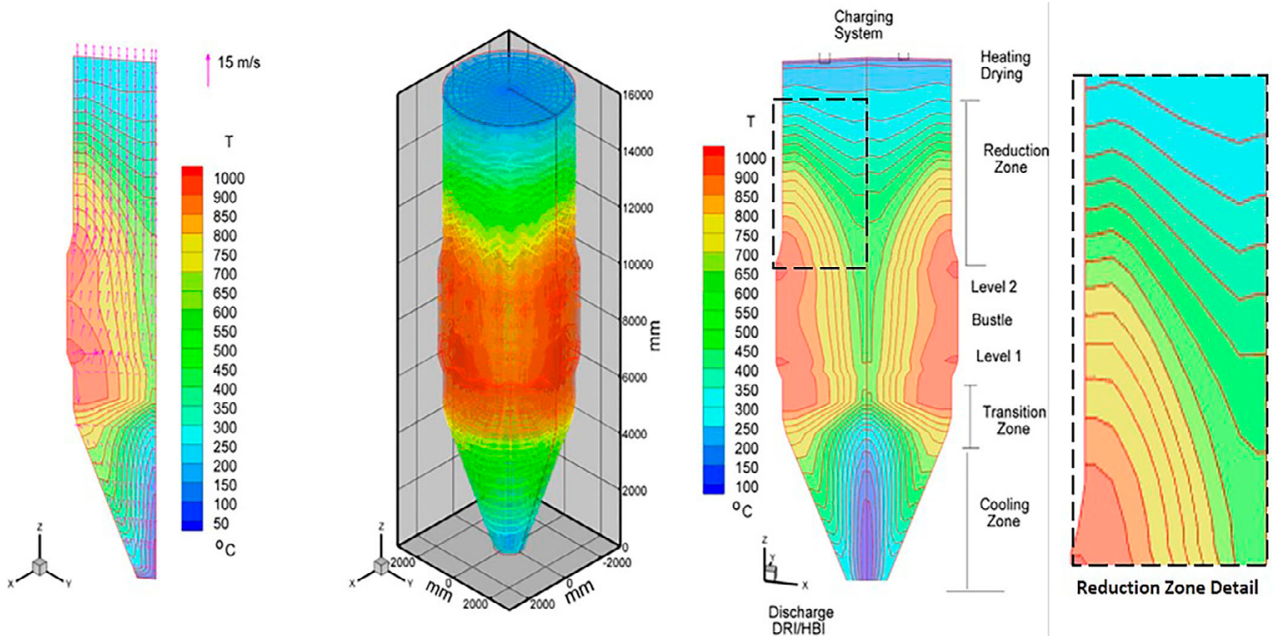

Figure 4. Temperature distribution of case A, containing $5 \%$ of self-reducing pellets. 

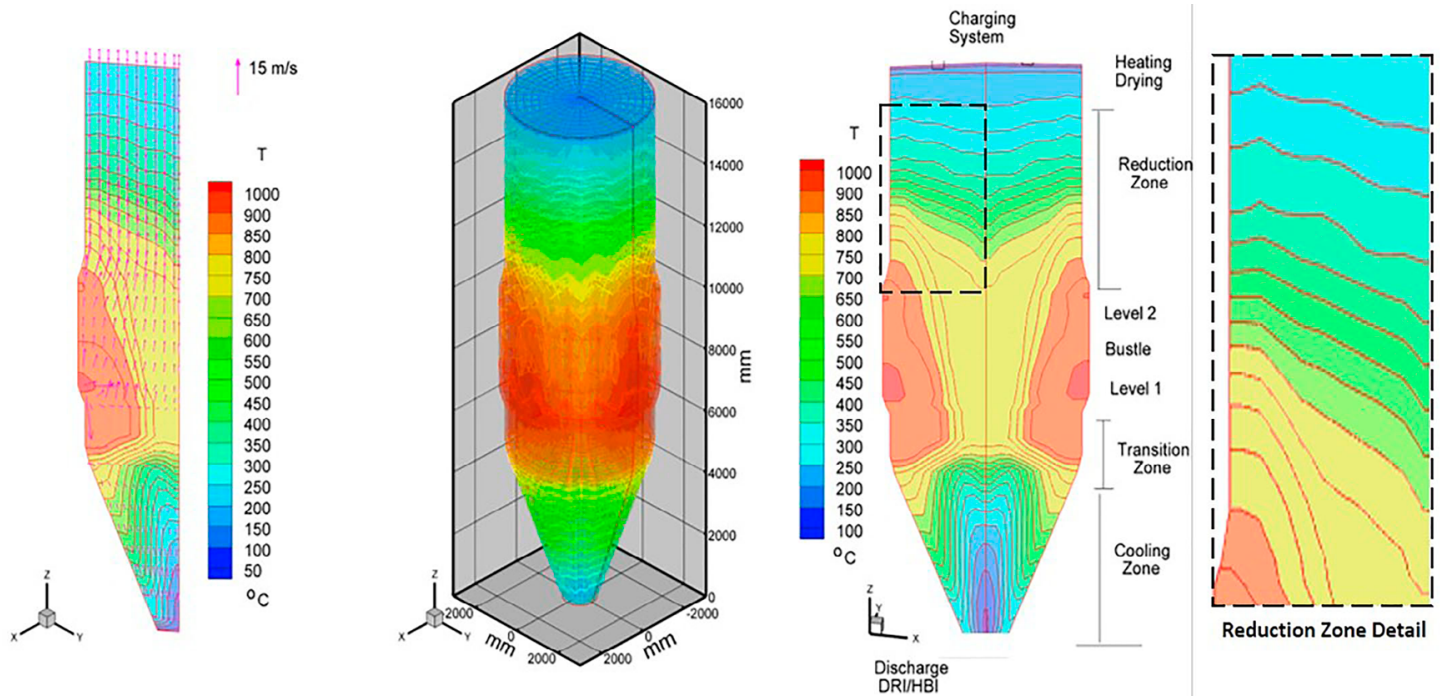

Figure 5. Temperature distribution of case B, in which $15 \%$ of the charge was replaced with self-reducing pellets, $2.5 \%$ of oxygen was added to the bustle gas, and the $\mathrm{CH}_{4}$ in the cooling gas was reduced by $50 \%$.
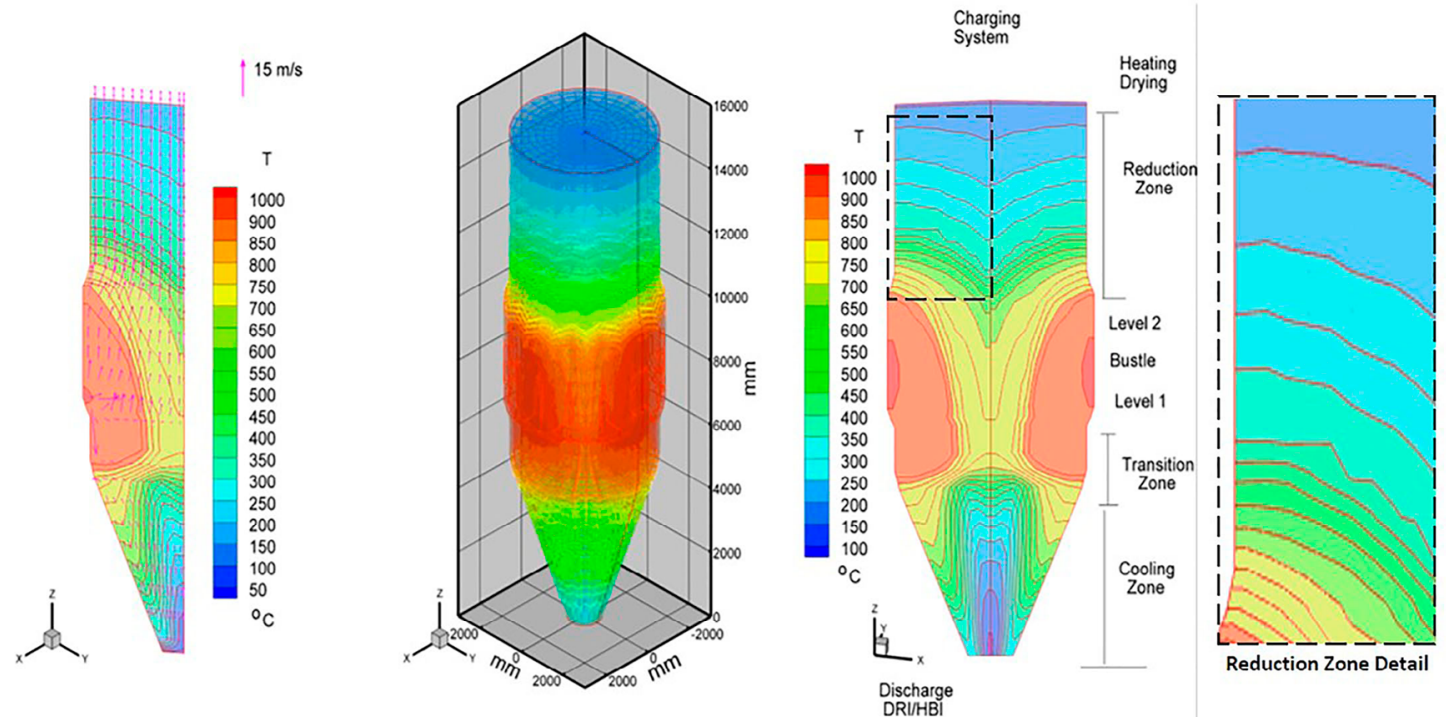

Figure 6. Temperature distribution of case $\mathrm{C}$, in which $15 \%$ of the charge was replaced with SRP, $2.5 \%$ of oxygen was added to the bustle gas, the $\mathrm{CH}_{4}$ in the cooling gas was reduced by $50 \%$, and the height of the reduction zone was decreased by $15 \%$.

auto-catalytic reactions and the partial combustion of the hydrogen and carbon monoxide to improve the heat transfer in the subsequent zones.

In addition, the fines of carbon in the agglomerates reduce the consumption of the cooling gas by $50 \%$, which is replaced by the treated gas (top outlet), since a part of the carburizing process involves the carbon present in the selfreducing pellets in the transition zone and the injected gas. This replacement saves natural gas from being consumed and helps maintain the pressure in the reduction zone.

For the cases represented in Fig. 5 and 6, additional oxygen was injected in the bustle zone. This allowed the increase of the self-reducing charge due to the energy gain from the oxygen reactions. An increase of the higher temperature region is observed in the central region of the reduction zone, compared to case A. However, the productivity of case C, compared to case $\mathrm{B}$, is increased by $5 \%$ for the same degree of metallization and volume of injected gas. Case $\mathrm{C}$ presents a great advantage compared to the previous cases, since the reactor can be resized based on the necessary requirements in order to avoid degradation of the load, since self-reducing pellets display lower mechanical resistances compared to that of DRI. In addition, it is expected that reducing the height of the furnace will also reduce the "sticking" phenomenon, which occurs when necks are formed between the pellets.

To increase the proportion of self-reducing pellets in the charge to $20 \%$, it is necessary to further reduce the height of the reduction zone to avoid charge degradation and attempt 
to recover the pressure loss in the charge by injecting more gas into the bustle. The results of cases $\mathrm{D}, \mathrm{E}$, and $\mathrm{F}$ can be seen in Fig. 7 and 8.

Fig. 7 shows that, upon replacement of the feed load with $20 \%$ of SRP, the temperature distribution throughout the reactor volume decreases; however, it is possible to resize the reactor up to a height $40 \%$ less than the initial height without any interference in the energy distribution of the equipment, compared to the previous case in which $30 \%$ of the height was reduced.

Case $\mathrm{F}$ is compared with case $\mathrm{E}$ in Fig. 8, and it is observed that when the amount of gas injected into the bustle increases, the temperature distribution remains unchanged in the reduction and transition zones, compared to that of case $\mathrm{E}$; however, there is an energy gain in the cooling zone, and the productivity of case $\mathrm{E}$ is almost $2 \%$ higher than that of case $\mathrm{F}$.

The residence time of the charge inside the reactor under usual operating conditions is about $6 \mathrm{~h}$, with the average productivity being approximately $12 \mathrm{ton} / \mathrm{m}^{3} /$ day. When comparing the cases $\mathrm{D}, \mathrm{E}$, and $\mathrm{F}$ with the base case, it is observed that the residence time of the charge inside the furnace decreases drastically to almost $50 \%$ of that inside a commercial reactor, as observed in Table 6.
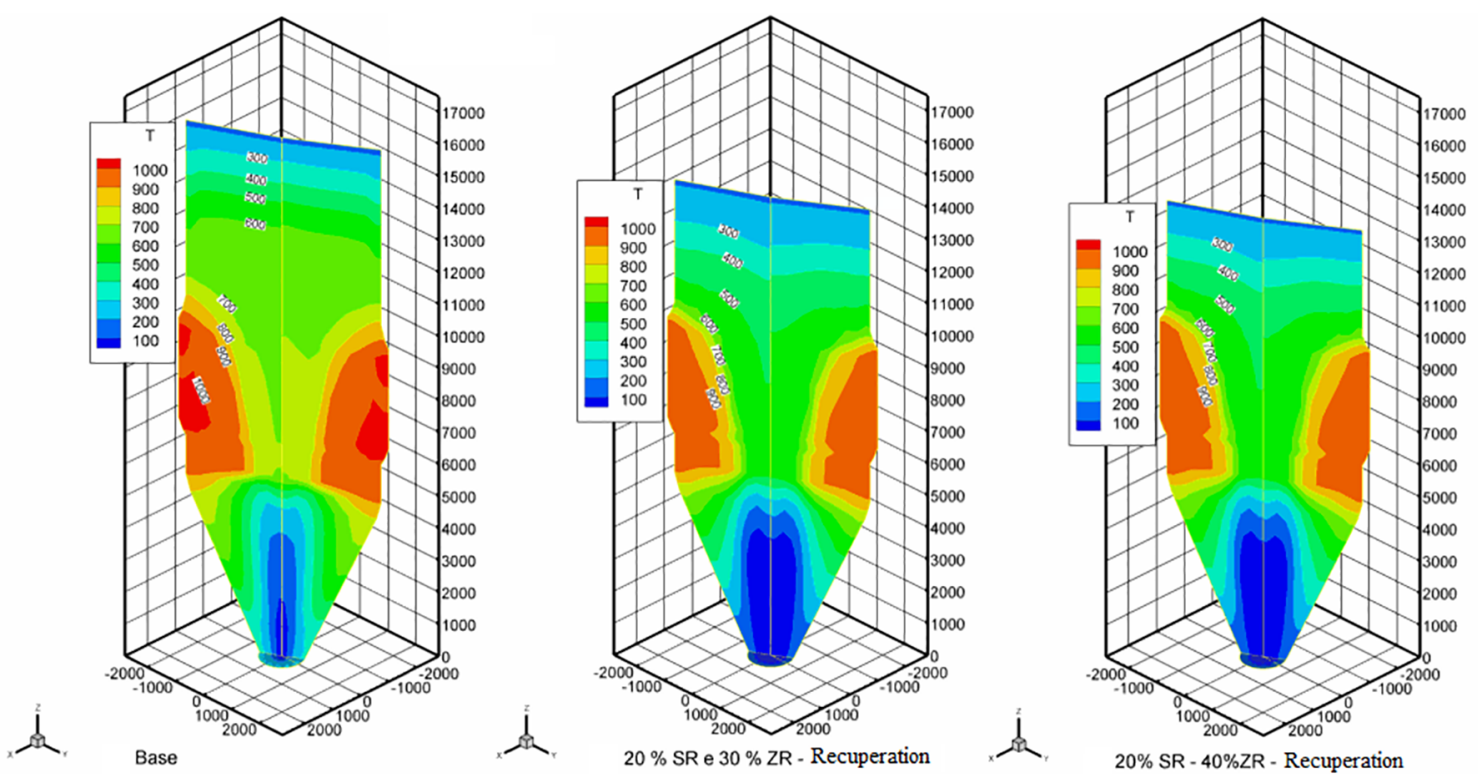

Figure 7. (a) Base case. Temperature distribution for $20 \%$ of the charge replaced with SRP; and (b) $30 \%$, case D, and (c) $40 \%$, case E, reductions in the height of the reduction zone.
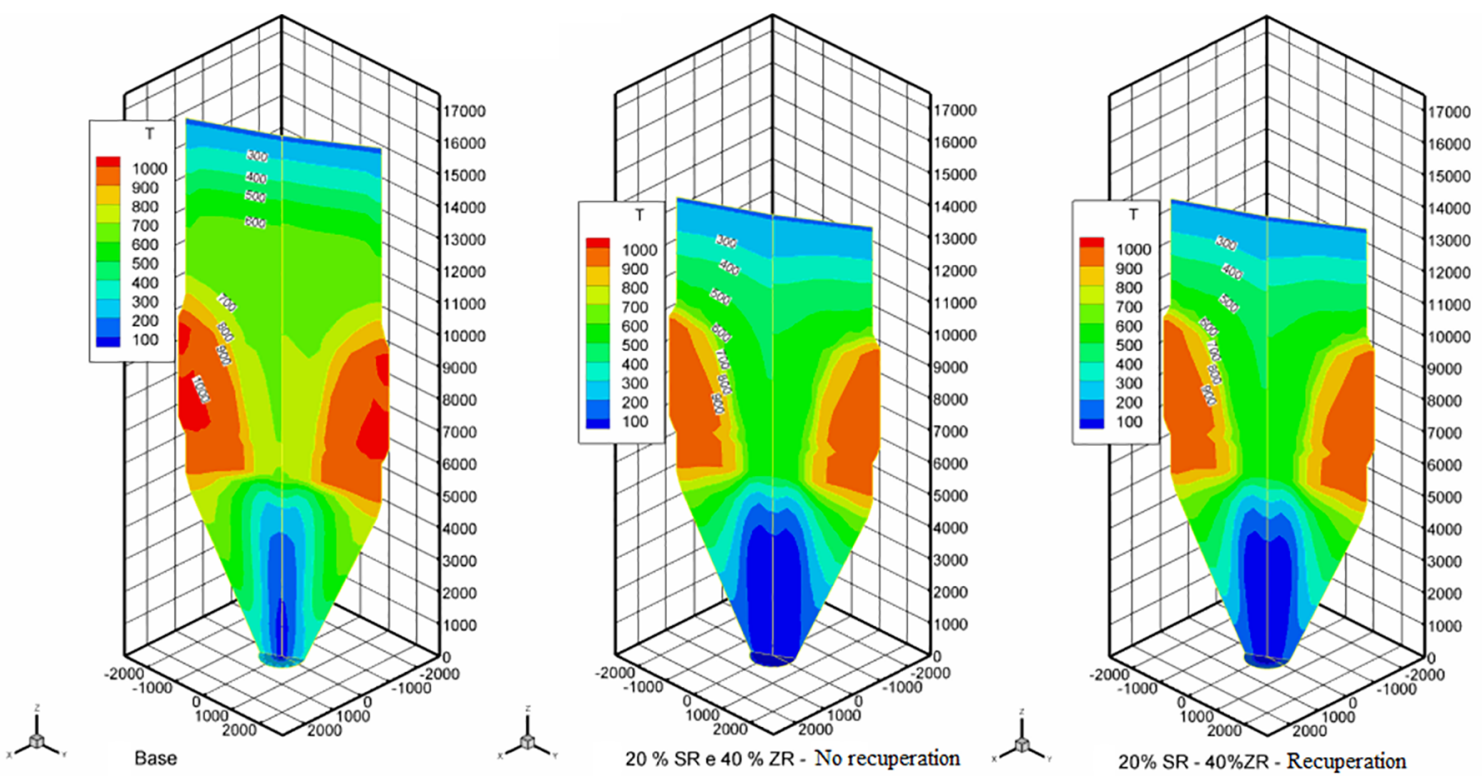

Figure 8. (a) Base case. Temperature distribution for $20 \%$ of the feed charge replaced with SRP; $40 \%$ reduction in the height of the reduction zone (b) without (case F) and (c) with (case E) gas recuperation. 
Table 6. Operating parameters obtained for the cases simulated in this study.

\begin{tabular}{|c|c|c|c|c|c|}
\hline \multirow[b]{2}{*}{ Parameters } & \multicolumn{5}{|c|}{ Cases } \\
\hline & & Base & Case D & Case $\mathbf{E}$ & Case $\mathbf{F}$ \\
\hline \multicolumn{2}{|l|}{ Productivity (ton $/ \mathrm{m}^{3} / \mathrm{dia}$ ) } & 11.85 & 13.41 & 14.53 & 13.09 \\
\hline \multicolumn{2}{|l|}{ Metallization (\%) } & $93.66 \%$ & $95.34 \%$ & $94.80 \%$ & $94.76 \%$ \\
\hline \multicolumn{2}{|c|}{ Average residence time $(\mathrm{h})$} & $5 \mathrm{~h} 57 \mathrm{~min}$ & $3 \mathrm{~h} 46 \mathrm{~min}$ & $3 \mathrm{~h} 09 \mathrm{~min}$ & $3 \mathrm{~h} 29 \mathrm{~min}$ \\
\hline \multicolumn{2}{|c|}{ Carbon Emission (kgC/tonDRI) } & 34.55 & 37.39 & 37.36 & 37.39 \\
\hline \multirow{6}{*}{$\begin{array}{l}\text { Composition of gas } \\
\text { bustle } \\
\text { (kg/tonDRI) }\end{array}$} & $\mathrm{CH}_{4}$ & 19.92 & 21.92 & 22.11 & 22.02 \\
\hline & $\mathrm{H}_{2}$ & 54.07 & 57.32 & 57.8 & 57.55 \\
\hline & $\mathrm{N}_{2}$ & 7.23 & 7.97 & 8.03 & 7.99 \\
\hline & $\mathrm{CO}$ & 466.03 & 513.09 & 517.33 & 515.17 \\
\hline & $\mathrm{CO}_{2}$ & 32.78 & 36.1 & 36.39 & 36.24 \\
\hline & $\mathrm{H}_{2} \mathrm{O}$ & 51.89 & 57.14 & 57.61 & 57.37 \\
\hline \multirow{6}{*}{$\begin{array}{l}\text { Composition of top gas } \\
\left(\mathrm{Nm}^{3} / \text { tonDRI }\right)\end{array}$} & $\mathrm{CH}_{4}$ & $9.6 \times 10^{-6}$ & $5.42 \times 10^{-4}$ & $1.04 \times 10^{-3}$ & $6.18 \times 10^{-4}$ \\
\hline & $\mathrm{H}_{2}$ & 19.47 & 25.72 & 26.05 & 25.84 \\
\hline & $\mathrm{N}_{2}$ & 0.51 & 0.49 & 0.49 & 0.49 \\
\hline & $\mathrm{CO}$ & 24.34 & 27.37 & 27.36 & 27.39 \\
\hline & $\mathrm{CO}_{2}$ & 10.21 & 10.02 & 10.00 & 10.00 \\
\hline & $\mathrm{H}_{2} \mathrm{O}$ & 43.79 & 33.29 & 32.96 & 33.16 \\
\hline
\end{tabular}

Specifically, case E was the best case obtained, since its productivity reached 2.7 tons $/ \mathrm{m}^{3} /$ day, which is higher than that of the base case; this case is also superior in terms of carbon emissions, compared with those of cases D and F.

Despite considerable increases in the $\mathrm{CO}_{2}$ and $\mathrm{CO}$ emissions through the outlet gas in all the cases in which the self-reducing load was considered, increasing concentration of the other gases characteristic of the synthesis gas in the outlet stream is also observed. This implies that the bustle flow can be further reduced or recovered after condensation of the water and reuse of the energy, thus improving the reduction potential. In addition, the carbonaceous source considered in the selfreducing pellets is not obtained from a fossil source, but from biomass, which is a renewable source.

\section{Conclusion}

This study investigated the energy gain and productivity improvement of shaft furnaces through computational simulations, when it is proposed the burden partial replacing by self-reducing agglomerates, containing CEG. For this purpose, the numerical model based on the governing equations transport within the reactor was implemented by using the kinetic parameters obtained experimentally ${ }^{18}$.

From the simulation results, it has been proven that the combination between self-reduction and self-reformation phenomenons in the direct reduction on shaft furnaces increase the productivity and decrease the residence time ${ }^{8-10}$ of the load inside the furnace in an abrupt manner.
Owing to the addition of these processes, it was possible to analyze the resizing of the reactor, the energy demand on reduction, and the increase in the productivity, and reasonably avoid degradation of the pellets and the so-called sticking phenomenon. In addition, the carbonaceous source is obtained from a renewable raw material, biomass of elephant grass, which replaces coke, a fossil source.

The consumption of natural gas in the cooling zone was reduced because a part of the carburizing of the load was carried out by the self-reducing pellets and a part of the cooling gas was replaced by the treated gas; the consumption also decreased owing to the re-dimensioning of the reactor, which lowered the demand for reformed gas.

\section{Acknowledgements}

The authors thank the funding agencies: Coordination of Improvement of Higher Education Personnel, (CAPES). They also thank the Metallurgical Engineering graduate program of the Fluminense Federal University for the scientific technical support.

\section{References}

1. Parisi DR, Laborde MA. Modeling of counter current moving bed gas-solid reactor used in direction reduction of iron ore. Chemical Engineering Journal. 2004;104:35-43.

2. Nouri SMM, Ale Ebrahim H, Jamshidi E. Simulation of direct reduction reactor by the grain model. Chemical Engineering Journal. 2011;166(2):704-709. 
3. Valipour MS, Saboohi Y. Numerical Investigation of nonisothermal reduction of hematite using syngas: the shaft scale study. Modelling and Simulation in Materials Science and Engineering. 2007;15(5):487-507.

4. Wu S, Xu J, Yang S, Zhou Q, Zhang LH. Basic characteristics of the shaft furnace of $\mathrm{COREX}^{\circledR}$ smelting reduction process based on iron oxides reduction simulation. ISIJ International. 2010;50:1032-1039.

5. Wu S, Xu J, Yagi J, Guo X, Zhang L. Prediction of pre-reduction shaft furnace with top gas recycling technology aiming to cut down $\mathrm{CO}_{2}$ emission. ISIJ International. 2011;51:1344-1352.

6. Ghadi AZ, Valipour MS, Biglari M. CFD simulation of twophase gas-particle flow in the Midrex shaft furnace: The effect of twin gas injection system on the performance of the reactor. International Journal of Hydrogen Energy. 2017;42(1):103-118.

7. Xu J, Wu S, Kou M, Du K. Numerical analysis of the characteristics inside pre-reduction shaft furnace and its operation parameters optimization by using a three-dimensional full scale mathematical model. ISIJ International. 2013;53(4):576-582.

8. Castro JA, Silva AJ, D’Abreu JC. Two-phase model and computational simulation of self-reduction in shaft furnace. Tecnologia em Metalurgia, Materiais e Mineração. 2006;2(4):45-50.

9. Castro JA, Paco LJM, D'Abreu JC. Investigation of the behavior of the shaft furnace for self-reducing process using the multiphase model. Tecnologia em Metalurgia, Materiais e Mineração. 2007;3(3):16-21.

10. Castro JA, Baltazar AWS, Silva AJ, D’Abreu JC, Yagi JI. Evaluation of the performance of the blast furnace operating with selfreducing pellets using the computational simulation. Tecnologia em Metalurgia, Materiais e Mineração. 2005;2(2):45-50.

11. Castro JA, Baltazar AWS. Numerical study of $\mathrm{CO}_{2}$ recycling into the combustion zone of the blast furnace. Tecnologia em Metalurgia, Materiais e Mineração. 2009;6(1):13-18.

12. Zhou P, Li HI, Shi PY, Zhou CQ. Simulation of the transfer process in the blast furnace shaft with layered burden. Applied Thermal Engineering. 2016;95:296-302.
13. Fu D, Chen Y, Zhao YF, D'Alessio J, Ferron KJ, Zhou CQ. CFD modeling of multiphase reacting flow in blast furnace shaft with layered burden. Applied Thermal Engineering. 2014;66(1-2):298308.

14. Austin PR, Nogami H, Yagi JI. A mathematical model of four phase motion and heat transfer in the blast furnace. ISIJ International. 1997;37(5):458-467.

15. Austin PR, Nogami H, Yagi JI. A mathematical model for blast reaction analysis based on the four fluid model. ISIJ International. 1997;37(8):748-755.

16. Castro JA, Nogami H, Yagi JI. Transient mathematical model of blast furnace based on multi-fluid concept, with application to high PCI operation. ISIJ International. 2000;40(7):637-646.

17. Matos UF, Castro JA. Modelamento da utilização de aglomerado autorredutor em minialto-forno com recirculação de gás de topo. Revista Escola de Minas. 2002;65(1):65-71.

18. Rocha EP, Castro JA, Vitoretti, FP, Junior FV. Kinetic of selfreducing mixtures of iron ore and biomass of elephant grass. Materials Science Forum. 2016;869:1007-1012.

19. Castro JA, Rocha EP, Oliveira EM, Campos MF, Francisco AS. Mathematical modeling of the shaft furnace process for producing DRI based on the multiphase theory. REM International Engineering Journal. 2018;71(1):81-87.

20. Man Y, Feng JX, Chen YM, Zhou JZ. Mass loss and direct reduction characteristics of iron ore coal composite pellets. Journal of Iron and Steel Research International. 2014;21(12):10901094.

21. Yi Man, Feng JX, Li FJ, Ge Q, Chen YM, Zhou JZ. Influence of temperature and time on reduction behavior in iron ore-coal composite pellets. Powder Technology. 2014;256:361-366.

22. Liu GS, Strezov V, Lucas JA, Wibberley LJ. Thermal investigations of direct iron ore reduction with coal. Thermochimica Acta. 2004;410(1-2):133-140.

23. Zuo HB, Hu ZW, Zhang JL, Li J, Liu ZJ. Direct reduction of iron ore by biomass char. International Journal of Minerals, Metallurgy and Materials. 2013;20:514-521. 